\title{
PENGARUH KUALITAS PELAYANAN LEMBAGA AMIL ZAKAT (LAZ) TERHADAP KEPUASAN DAN LOYALITAS MUZAKKI (STUDI KASUS LAZ PKPU YOGYAKARTA)
}

\author{
Sutomo $^{*}$, , Mukhamad Najib ${ }^{* *}$, dan Setiadi Djohar $\left.{ }^{* * *}\right)$ \\ *) Departemen Arsitektur Lanskap, Fakultas Pertanian, Institut Pertanian Bogor \\ Jl. Meranti Kampus IPB Dramaga, Bogor 16680 \\ **) Departemen Manajemen, Fakultas Ekonomi dan Manajemen, Institut Pertanian Bogor \\ Jl. Kamper, Wing 2 Level 5 Kampus IPB Darmaga, Bogor 16680 \\ ${ }^{* * *)}$ PPM Manajemen \\ Jl. Menteng Raya No. 9 Jakarta Pusat 10340
}

\begin{abstract}
The zakat revenue achievement in Indonesia is always a topic among the government, humanitarian agencies and zakat institution. The zakat institution is required to have an innovative and creative program as well as improving the services quality to show the best condition, The healthy condition of the zakat institutions will attract muzakki (a person who is obliged to give the zakat) to contribute his/her fund through the institutions. The objectives of the research are to 1) analyze factors that influence the Muzakki's level of satisfaction in the LAZ PKPU Yogyakarta services, 2) analyze the satisfaction level of the Muzakki for the LAZ PKPU Yogyakarta services, 3) analyze the Muzakki's level of loyalty for the LAZ PKPU Yogyakarta services, 4) formulate a better strategy to increase the satisfaction service for the muzakki. The research is using questionnaires that are then analyzed using Structural Equation Method (SEM) and the Importance Performance Analysis (IPA). The result of the research shows that there are four dimensions i.e.; Compliance, Assurance, Reliability and Empathy have a significant effect on the satisfaction. The IPA analysis also shows that the zakat service performance needs to be increased and the muzakki's complaint needs to be followed up quickly. The results also show that the muzakki's satisfaction, shows the loyalty and satisfaction index value by $82.34 \%$ This means that the muzakki is satisfied with the service provided and the muzakki's loyalty level is $84,7 \%$ is the sign that the muzakki loyalty to the LAZ PKPU Yogyakarta.
\end{abstract}

Keywords: LAZ, satisfaction, loyalty, SEM, IPA

\begin{abstract}
ABSTRAK
Pencapaian penerimaan zakat di Indonesia selalu menjadi pembicaraan hangat antara pemerintah, lembaga kemanusiaan dan lembaga zakat. Lembaga zakat dituntut membuat program yang inovatif dan kreatif serta meningkatkan kualitas pelayanan yang diberikan untuk menunjukkan kondisi yang terbaik. Kondisi lembaga zakat yang baik dapat menarik Muzakki untuk menyalurkan dananya ke lembaga. Tujuan dari penelitian ini ialah 1) menganalisis faktor yang Memengaruhi kepuasan Muzakki terhadap pelayanan LAZ PKPU Yogyakarta; 2) menganalisis tingkat kepuasan Muzakki atas pelayanan yang telah diberikan LAZ PKPU Yogyakarta; 3) menganalisis tingkat loyalitas Muzakki atas pelayanan yang telah diberikan LAZ PKPU Yogyakarta; 4) merumuskan strategi yang perlu dilakukan LAZ PKPU Yogyakarta dalam rangka meningkatkan pelayanan yang lebih baik bagi Muzakki. Instrumen penelitian ini menggunakan kuesioner dan dianalisis dengan Structural Equation Modeling (SEM) dan Importance Performance Analysis (IPA). Hasil penelitian menunjukkan bahwa empat dimensi yaitu Compliance, Assurance, Reliability dan Empathy memiliki pengaruh signifikan terhadap kepuasan. Hasil analisis IPA menunjukkan bahwa atribut pelayanan yang harus ditingkatkan kinerjanya yaitu permasalahan zakat diselesaikan dengan cepat dan segera dan karyawan merespon dan menindaklanjuti keluh kesah. Penelitian ini juga menunjukkan bahwa kepuasan Muzakki Memengaruhi loyalitas dan nilai indeks kepuasan Muzakki sebesar 82,34\% yang berarti bahwa Muzakki telah merasa puas dengan pelayanan yang diberikan dan tingkat loyalitas Muzakki sebesar 84,7\% yang berarti bahwa Muzakki telah loyal kepada LAZ PKPU Yogyakarta.
\end{abstract}

Kata kunci: LAZ, kepuasan, loyalitas, SEM, IPA

\footnotetext{
${ }^{1}$ Alamat Korespondensi:

Email: abifadhil234@gmail.com
} 


\section{PENDAHULUAN}

Zakat merupakan rukun Islam yang ketiga dan menjadi salah satu kewajiban yang harus ditunaikan oleh umat Islam. Kewajiban tersebut telah ada sejak masa Rasulullah dan para sahabat sampai dengan nanti di akhir zaman seperti yang diperintahkan Allah dan Rasulullah SAW. Salah satu ayat dalam Alqur'an yang menegaskan tentang kewajiban zakat terdapat dalam Surat At Taubah ayat 103: "Ambillah zakat dari sebagian harta mereka, dengan zakat itu kamu membersihkan dan mensucikan mereka dan mendoalah untuk mereka. Sesungguhnya doa kamu itu (menjadi) ketenteraman jiwa bagi mereka dan Allah Maha mendengar lagi Maha Mengetahui."

Kewajiban zakat memiliki arti penting dalam ajaran Islam. Selain merupakan hubungan vertikal antara seorang hamba dengan Allah SWT, zakat juga berperan dalam perekonomian dengan menjadi sarana pemerataan pendapatan di antara umat Islam. Zakat diharapkan mampu untuk mengurangi jumlah kemiskinan, meningkatkan kesejahteraan rakyat, menghilangkan sifat kikir dari yang memiliki harta dan mempererat hubungan silaturahmi sesama umat Islam. Sesuai penelitian Beik (2009), zakat terbukti mampu mengurangi jumlah keluarga miskin dari 84\% menjadi $74 \%$ serta mengurangi kesenjangan kemiskinan dan kesenjangan pendapatan.

Indonesiamerupakansalahsatunegara dengan penduduk muslim terbesar di dunia. Dari data pertumbuhan bank dunia tahun 2012, jumlah seluruh penduduk Indonesia mencapai 244.775 .796 jiwa dengan $88 \%$ diantaranya atau 182.570.000 jiwa memeluk agama Islam (muslim). Hal ini menjadi salah satu potensi besar yang dimiliki Indonesia dalam melaksanakan pembangunan serta mewujudkan masyarakat adil dan makmur.

Berdasarkan penelitian dari Baznas dan IPB tahun 2010, potensi zakat di Indonesia mencapai Rp217 Triliun per tahun dan saat ini jumlah yang terkumpul per tahun hanya sebesar $1 \%$ dari potensi yang ada. Selain itu, berdasarkan survei PIRAC tahun 2007, tingkat kesadaran pemberi zakat (muzakki) di Indonesia masih rendah, yaitu 55\%. Hal ini masih sangat kecil karena kesadaran itu belum termasuk kemauan muzakki untuk membayar zakat yaitu 95,5\% dari 55\% tersebut. Kondisi ini menjadi tanggung jawab umat Islam bersama pemerintah, ulama dan seluruh lapisan masyarakat.

Adnan (2001) menyebutkan tentang penyebab rendahnya tingkat kolektibillitas zakat di Indonesia yaitu rendahnya pengetahuan dan pemahaman masyarakat tentang zakat. Hal ini merupakan dampak dari kurangnya pendidikan agama dan pengamalan ajaran agama Islam dalam kehidupan sehari-hari. Penyebab lainnya ialah dari aspek kelembagaan zakat, dimana dibutuhkan organisasi pengelola zakat yang mampu bekerja secara profesional dan sesuai syariah Islam mulai dari perhitungan, pengumpulan dan pendistribusian zakat sehingga menimbulkan kepercayaan dari masyarakat.

Menurut Bramasetia (2014), banyaknya LAZ tidak menimbulkan persaingan namun memberikan pilihan kepada masyarakat untuk menyalurkan zakatnya melalui lembaga zakat yang dipercayai sehingga setiap LAZ akan berusaha menunjukkan program dan kinerja yang optimal dalam pengelolaan zakat. LAZ juga akan berusaha menjaga kepuasan muzakki dalam menyalurkan zakatnya sehingga tidak berpindah ke lembaga zakat lain atau menyalurkannya secara langsung kepada penerima zakat (mustahik).

LAZ yang amanah, bertanggungjawab dan memiliki kredibilitas, dapat menyebabkan masyarakat percaya dan menyalurkan zakatnya. Jika pelayanan yang diberikan juga memuaskan, tentunya masyarakat akan puas serta semakin percaya dan loyal dalam menyalurkan zakatnya melalui lembaga tersebut. Oleh karena itu, penelitian terkait pengaruh kualitas pelayanan LAZ terhadap kepuasan dan loyalitas muzakki menjadi penting untuk dilakukan.

Penelitian terkait kualitas pelayanan terhadap kepuasan dan loyalitas sebelumnya pernah dilakukan diantaranya oleh Aryani dan Rosinta (2010), Ashari H et al. (2013), Despriyatmoko G et al. (2016) dan Ristanti V et al. (2011). Keempatnya ingin mengetahui dimensi kualitas pelayanan yang berpengaruh terhadap kepuasan dan loyalitas pelanggan. Yang membedakan penelitian ini dengan penelitian sebelumnya ialah adanya dimensi compliance dalam kualitas pelayanan, analisis data yang digunakan dan objek penelitian. 
Tujuan dari penelitian ini, ialah 1) menganalisis faktor yang Memengaruhi kepuasan muzakki terhadap pelayanan LAZ PKPU Yogyakarta; 2) menganalisis tingkat kepuasan muzakki atas pelayanan yang telah diberikan LAZ PKPU Yogyakarta; 3) menganalisis tingkat loyalitas muzakki atas pelayanan yang telah diberikan LAZ PKPU Yogyakarta; 4) merumuskan strategi yang perlu dilakukan LAZ PKPU Yogyakarta dalam rangka meningkatkan pelayanan yang lebih baik bagi muzakki.

Ruang lingkup penelitian ini difokuskan pada pengaruh pelayanan LAZ terhadap kepuasan dan loyalitas muzakki dengan studi kasus pada LAZ PKPU Yogyakarta. Dimensi kualitas pelayanan yang disampaikan oleh Othman dan Owen (2002) dijadikan rujukan dalam penelitian ini.

\section{METODE PENELITIAN}

Penelitian ini difokuskan pada pengaruh pelayanan LAZ terhadap kepuasan dan loyalitas muzakki (Studi kasus LAZ PKPU Yogyakarta). Masyarakat yang menjadi responden merupakan muzakki yang terdaftar di LAZ PKPU Yogyakarta pada tahun 2015. Lokasi penelitian berada di kantor LAZ PKPU Yogyakarta dengan rentang waktu selama empat bulan mulai bulan Desember 2015 sampai dengan Maret 2016 untuk penyusunan kuesioner, wawancara dan observasi langsung, pengisian kuesioner serta pengolahan data. Penelitian ini menggunakan pendekatan metode survei, dimana data dikumpulkan melalui instrumen kuesioner oleh tim relawan PKPU Yogyakarta yang bertemu langsung dengan para muzakki.

Data yang digunakan dalam penelitian ini ialah data primer dan data sekunder. Data primer diperoleh melalui pengamatan langsung, wawancara dan pengisian kuesioner. Data sekunder diperoleh dari data yang telah diolah pihak lain atau yang telah dipublikasikan seperti profil lembaga amil zakat serta data operasional dan keuangan.

Metode pengambilan sampel dilakukan dengan cara nonprobability sampling dan prosedur yang digunakan ialah convenience sampling. Menurut Sugiarto, Siagian D, Sunaryanto LT, Oetomo DS (2001), nonprobability sampling merupakan penarikan sampel secara tak acak yang dapat dilakukan oleh peneliti dengan pertimbangan terkait penghematan biaya, waktu, tenaga dan keterandalan subyektifitas peneliti. Pada prosedur convenience sampling, sampel diambil berdasarkan pada ketersediaan responden dan kemudahan untuk mendapatkannya.

Jumlah populasi dalam penelitian ini sebanyak 4.211 muzakki PKPU yang tinggal di wilayah Yogyakarta dan sekitarnya. Jumlah sampel dalam penelitian ini disesuaikan dengan metode analisis yang digunakan, yaitu Structural Equation Modeling (SEM). Merujuk pada pendapat Hair JFJ et al. (2006), jumlah sampel dalam penelitian minimal lima kali dari jumlah variabel teramati. Pada penelitian ini terdapat 25 variabel sehingga jumlah sampel yang dibutuhkan minimal sebanyak 125 sampel.

Penelitian ini mengkaji variabel kepuasan muzakki terhadap kualitas pelayanan LAZ. Dimensi kualitas pelayanan yang digunakan ialah CARTER(Compliance, Assurance, Reliability, Tangibles, Empathy dan Responsiveness) sesuai Othman dan Owen (2002). Keenam dimensi tersebut menjadi faktor independen (variabel laten), sedangkan kepuasan dan loyalitas muzakki menjadi faktor dependen. Setiap indikator yang menjadi variabel akan diukur melalui pengolahan data yang didapat dari kuesioner yang disebarkan dengan menggunakan skala Likert 1-5 mulai dari sangat tidak setuju, tidak setuju, ragu-ragu, setuju dan sangat setuju.

Untuk menentukan prioritas indikator yang dianggap penting oleh muzakki sebagai dasar peningkatan kualitas pelayanan LAZ digunakan metode Importance Performance Analysis (IPA) yang digambarkan dalam diagram kartesius.

Pelayanan LAZ merupakan salah satu hal yang menjadi daya tarik muzakki dalam menyetorkan zakatnya. Sesuai visi dan misi PKPU, yaitu menjadi lembaga terpercaya dalam membangun kemandirian maka kepercayaan akan timbul jika PKPU dapat memberikan pelayanan yang optimal kepada muzakki. Kualitas pelayanan ditentukan dengan indikator sesuai enam dimensi CARTER yang akan menunjukkan kinerja kualitas dari PKPU dan berpengaruh terhadap kepuasan dan loyalitas muzakki. Hasil analisis kepuasan dan loyalitas muzakki akan dapat dijadikan acuan dalam merumuskan strategi pelayanan yang lebih baik. Kerangka pemikiran dari penelitian ini dapat dilihat pada Gambar 1. 


\section{HASIL}

\section{Karakteristik Responden Berdasarkan Demografi}

Jumlah responden dalam penelitian ini sebanyak 134 responden yang terdiri dari responden pria sebanyak 60 orang $(44,8 \%)$ dan wanita sebanyak 74 orang $(55,2 \%)$, dengan usia mayoritas antara 30 sampai 40 tahun. Responden umumnya telah menikah sebanyak 77,6\% dengan tingkat pendidikan Sarjana, profesi umumnya sebagai pegawai swasta dengan penghasilan kurang dari Rp10 juta.

\section{Uji Validitas dan Reliabilitas}

Uji validitas bertujuan untuk menentukan tingkat kemampuan suatu indikator dalam mengukur variabel latennya sedangkan uji reliabilitas bertujuan untuk mengukur tingkat konsistensi suatu indikator dalam mengukur konstruk latennya. Sesuai uji validitas dan reliabilitas, terlihat bahwa seluruh variabel teramati dimensi CARTER telah valid karena memiliki nilai loading factor $\geq 0,50$ dan reliabilitas baik dengan nilai construc reliability $\geq 0,70$ dan variance extracted $\geq$ 0,50 . Hasil untuk uji validitas dan reliabilitas secara lengkap dapat dilihat pada Tabel 1.

\section{Uji Goodness of Fit}

Ukuran kesesuaian model SEM, menurut Hair JFJ et al. (2006), tidak ada uji statistik tunggal untuk mengukur atau menguji keseluruhan model sehingga dapat digunakan beberapa ukuran kriteria kesesuaian yang dapat digunakan untuk saling mendukung, yang mencerminkan apakah data yang ada mendukung model penelitian yang telah ditetapkan. Beberapa ukuran kriteria kesesuaian keseluruhan model yang dapat digunakan ialah dengan menggunakan sembilan indikator goodness of fit dari output Lisrel seperti dalam Tabel 2. Hal ini menunjukkan seluruh indikator menunjukkan bahwa model SEM sudah baik. Data hasil kuesioner sudah mampu menjawab teori yang dibangun.

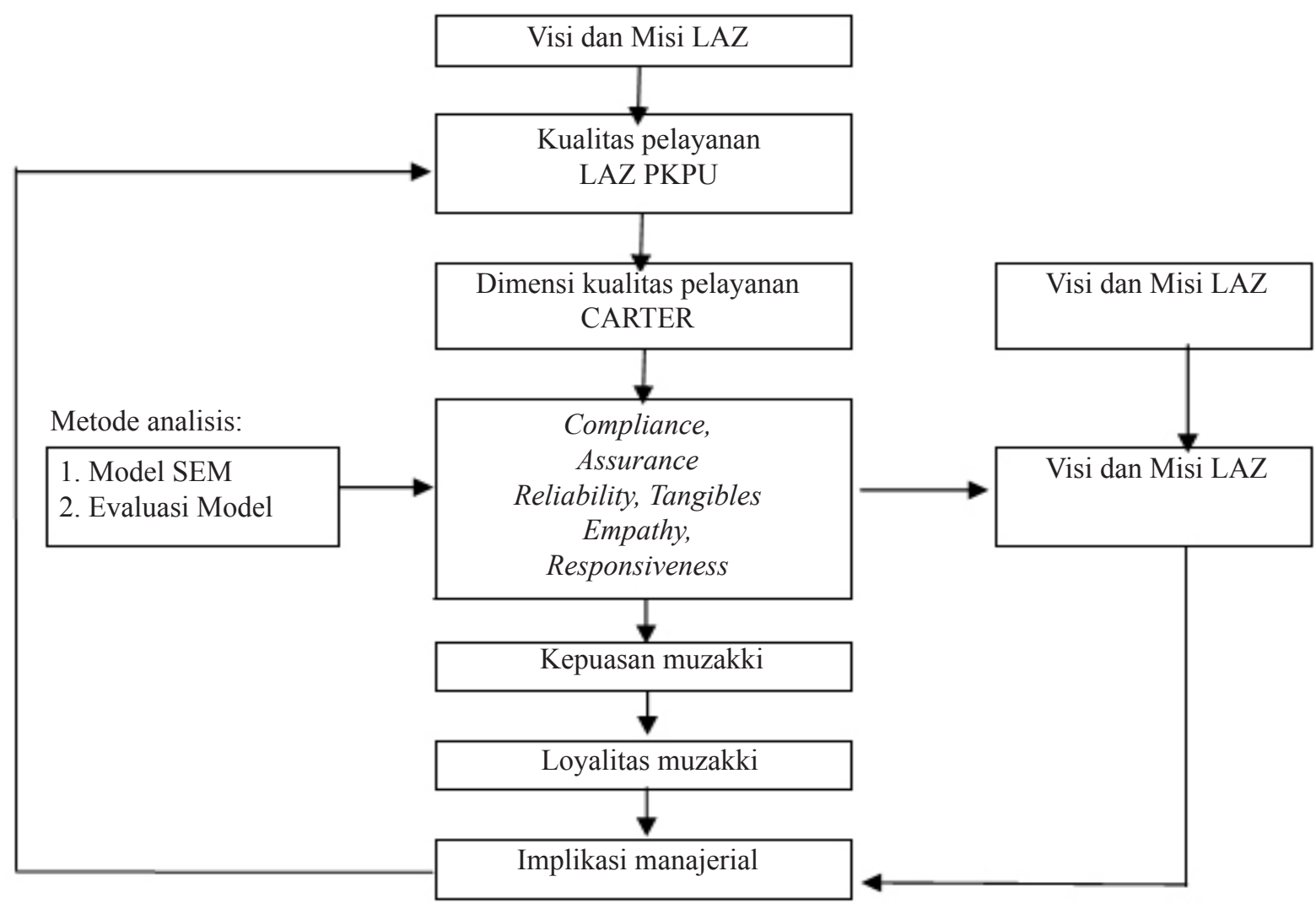

Gambar 1. Kerangka pemikiran penelitian 
Tabel 1. Uji validitas dan reliabilitas

\begin{tabular}{|c|c|c|c|c|}
\hline Kode & Indikator & $\begin{array}{l}\text { Loading } \\
\text { factor }\end{array}$ & $\begin{array}{l}\text { Construct } \\
\text { reliability }\end{array}$ & $\begin{array}{l}\text { Variance } \\
\text { extracted }\end{array}$ \\
\hline & Compliance & & \multirow{6}{*}{0,845} & \multirow{6}{*}{0,579} \\
\hline $\mathrm{X} 1$ & Pelaksanaan akad sesuai syariat Islam & 0,80 & & \\
\hline $\mathrm{X} 2$ & Perhitungan zakat sesuai syariat Islam & 0,84 & & \\
\hline $\mathrm{X} 3$ & Distribusi zakat sesuai syariat Islam & 0,77 & & \\
\hline $\mathrm{X} 4$ & Media komunikasi dan sosialisasi zakat sesuai syariat Islam & 0,65 & & \\
\hline & Assurance & & & \\
\hline X5 & Karyawan ramah dan berprilaku sopan & 0,66 & \multirow{4}{*}{0,831} & \multirow{5}{*}{0,566} \\
\hline $\mathrm{X} 6$ & Karyawan memahami hukum zakat & 0,95 & & \\
\hline $\mathrm{X} 7$ & Karyawan mampu memberikan penjelasan dan perhitungan zakat & 0,83 & & \\
\hline $\mathrm{X} 8$ & Jumlah karyawan mencukupi & 0,49 & & \\
\hline & Reliability & & & \\
\hline X9 & Selalu menepati janji & 0,73 & \multirow{5}{*}{0,835} & \multirow{5}{*}{0,563} \\
\hline $\mathrm{X} 10$ & Fasilitas layanan online & 0,60 & & \\
\hline $\mathrm{X} 11$ & Fasilitas layanan jemput zakat & 0,77 & & \\
\hline $\mathrm{X} 12$ & Jika kesulitan, PKPU memberikan penjelasan dan solusi & 0,87 & & \\
\hline & Tangible & & & \\
\hline $\mathrm{X} 13$ & Kondisi kantor rapih, bersih dan teratur & 0,91 & \multirow{5}{*}{0,839} & \multirow{5}{*}{0,582} \\
\hline $\mathrm{X} 14$ & Ruang penerima tamu nyaman & 0,95 & & \\
\hline $\mathrm{X} 15$ & Fasilitas parkir nyaman & 0,60 & & \\
\hline $\mathrm{X} 16$ & Bukti bayar dengan print out & 0,50 & & \\
\hline & Empathy & & & \\
\hline $\mathrm{X} 17$ & Jam operasional yang memudahkan & 0,72 & \multirow{5}{*}{0,890} & \multirow{5}{*}{0,671} \\
\hline $\mathrm{X} 18$ & Memberikan pemahaman zakat yang mudah dipahami & 0,88 & & \\
\hline X19 & Menerima kritik dan saran & 0,89 & & \\
\hline $\mathrm{X} 20$ & Publikasi dana zakat yang dihimpun & 0,77 & & \\
\hline & Responsiveness & & & \\
\hline $\mathrm{X} 21$ & Permasalahan zakat diselesaikan dengan cepat dan segera & 0,67 & \multirow{5}{*}{0,819} & \multirow{5}{*}{$\begin{array}{c}0,481 \\
\text { (dapat } \\
\text { dibulatkan } \\
0,5)\end{array}$} \\
\hline $\mathrm{X} 22$ & Karyawan merespon dan menindaklanjuti keluh kesah & 0,53 & & \\
\hline $\mathrm{X} 23$ & Brosur dan proposal dikirim melalui SMS dan pos & 0,70 & & \\
\hline $\mathrm{X} 24$ & Laporan dikirim melalui pos dan email & 0,64 & & \\
\hline $\mathrm{X} 25$ & Ketersediaan brosur, leaflet yang informatif & 0,88 & & \\
\hline
\end{tabular}

Tabel 2. Hasil kriteria kesesuaian model SEM

\begin{tabular}{lccc}
\hline \multicolumn{1}{c}{ Kriteria } & Cutt-off-value & Hasil & Keterangan \\
\hline Goodness of Fit Index (GFI) & $\geq 0,90$ & 0,97 & Good fit \\
Root Mean Square Residual (RMSR) & $\geq 0,05$ & 0,078 & Marginal fit \\
Root Mean square Error of Approximation (RMSEA) & $\geq 0,08$ & 0,064 & Good fit \\
Adjusted Goodness of Fit Index (AGFI) & $\geq 0,90$ & 0,93 & Good fit \\
Comparative Fit Index (CFI) & $\geq 0,90$ & 1,00 & Good fit \\
Tucker Lewis Index (TLI) & $\geq 0,90$ & 1,00 & Good fit \\
Normed Fit Index (NFI) & $\geq 0,90$ & 1,00 & Good fit \\
Incremental Fit Index (IFI) & $\geq 0,90$ & 1,00 & Good fit \\
Relative Fit Index (RFI) & $\geq 0,90$ & 1,00 & Good fit \\
\hline
\end{tabular}




\section{Model Struktural Kepuasan Pelanggan}

Pada penelitian ini, teknik analisis data menggunakan model SEM yang dioperasikan melalui program Linear Structural Relationship (LISREL). Model struktural dan nilai faktor muatan model dari data yang telah diolah ditampilkan pada Gambar 2. Faktor muatan model, yaitu koefisien yang menunjukkan seberapa besar tingkat kontribusi relatif dari masing-masing variabel indikator dalam membentuk variabel laten. Semakin besar nilainya menunjukkan semakin besar kontribusinya dalam membentuk variabel laten.
Sesuai Gambar 2, pada dimensi compliance, indikator perhitungan zakat sesuai syariat Islam memiliki faktor muatan yang paling besar, yaitu 0,85 yang berarti bahwa indikator ini yang memberikan kontribusi yang relatif lebih besar dibanding indikator lainnya. Sebaliknya, indikator yang relatif rendah pengaruhnya ada dua dengan nilai yang sama sebesar 0,77 , yaitu pelaksanaan akad sesuai syariat Islam dan media komunikasi dan sosialisasi zakat sesuai syariat Islam.

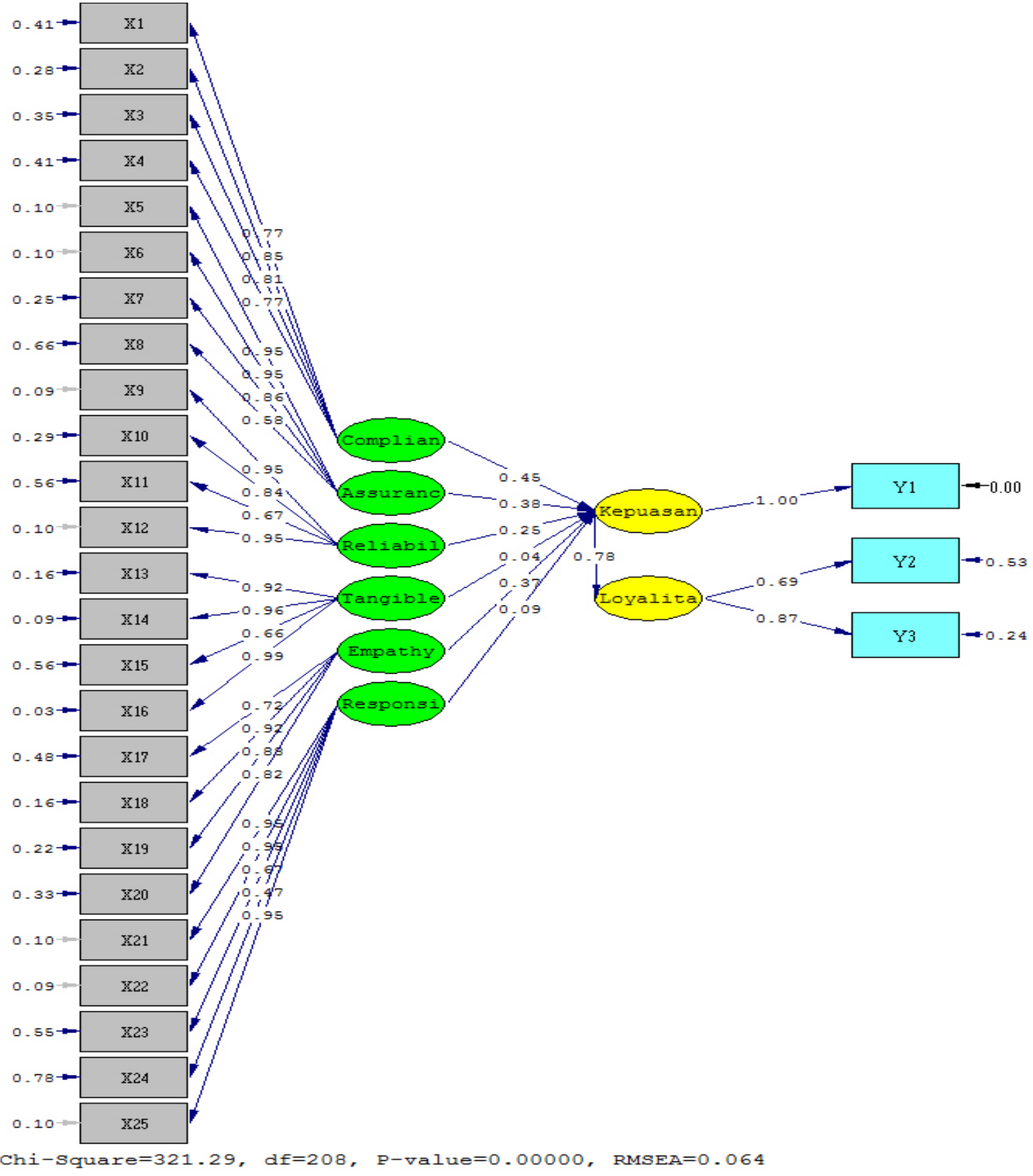

Gambar 2. Faktor muatan model 
Pada dimensi assurance, indikator karyawan ramah dan berprilaku sopan memiliki faktor muatan yang sama dengan karyawan memahami hukum zakat, yaitu 0,95 yang berarti bahwa indikator ini yang memberikan kontribusi yang relatif lebih besar dibanding indikator lainnya. Indikator yang relatif paling rendah, yaitu jumlah karyawan mencukupi dengan nilai sebesar 0,58 . Hal ini menunjukkan bahwa indikator tersebut memiliki pengaruh yang relatif paling kecil dalam membentuk dimensi assurance.

Pada dimensi reliability, indikator selalu menepati janji memiliki faktor muatan yang sama dengan indikator jika kesulitan, PKPU memberikan penjelasan dan solusi, yaitu 0,95 yang berarti bahwa indikator ini yang memberikan kontribusi yang relatif lebih besar dibanding indikator lainnya. Indikator yang relatif paling rendah, yaitu fasilitas layanan jemput zakat dengan nilai sebesar 0,67. Hal ini menunjukkan bahwa indikator tersebut memiliki pengaruh yang relatif paling kecil dalam membentuk dimensi reliability.

Untuk dimensi tangible, indikator bukti bayar dengan print out memiliki faktor muatan sebesar 0,99 yang berarti bahwa indikator ini yang memberikan kontribusi yang relatif lebih besar dibanding indikator lainnya. Indikator yang relatif paling rendah, yaitu fasilitas parkir nyaman dengan nilai sebesar 0,66 yang menunjukkan bahwa indikator tersebut memiliki pengaruh yang relatif paling kecil.

Pada dimensi empathy, indikator memberikan pemahaman zakat yang mudah dipahami memiliki faktor muatan sebesar 0,92 yang berarti bahwa indikator ini yang memberikan kontribusi yang relatif lebih besar dibanding indikator lainnya. Indikator yang relatif paling rendah, yaitu jam operasional yang memudahkan dengan nilai sebesar 0,72 , yang menunjukkan bahwa indikator tersebut memiliki pengaruh yang relatif paling kecil.
Pada dimensi responsiveness, indikator permasalahan zakat diselesaikan dengan cepat dan segera memiliki faktor muatan yang sama dengan ketersediaan brosur, leaflet yang informatif, yaitu 0,95 yang berarti bahwa indikator tersebut yang memberikan kontribusi yang relatif lebih besar dibanding indikator lainnya. Sedangkan indikator yang relatif paling rendah, yaitu laporan dikirim melalui pos dan email dengan nilai sebesar 0,47 . Hal ini menunjukkan bahwa indikator tersebut memiliki pengaruh yang relatif paling kecil dalam membentuk dimensi responsiveness.

\section{Faktor yang Memengaruhi Kepuasan Muzakki Terhadap Pelayanan LAZ PKPU Yogyakarta}

Hasil nilai t hitung dari analisis SEM dalam Tabel 3 menunjukkan dimensi Assurance merupakan dimensi yang memiliki nilai uji t tertinggi sebesar 7,24 yang berarti bahwa dimensi ini yang memberikan pengaruh positif dan paling signifikan terhadap kepuasan muzakki. Dimensi selanjutnya yang berpengaruh terhadap kepuasan muzakki ialah compliance, empathy dan reliability. Kepuasan yang dirasakan oleh muzakki tidak dipengaruhi oleh dimensi tangible dan responsiveness, dengan nilai uji t lebih kecil dari 1,96, yang berarti kedua variabel tersebut tidak memiliki hubungan yang signifikan dengan kepuasan. Hubungan yang tidak berpengaruh signifikan antara dimensi kualitas pelayanan terhadap kepuasan bisa disebabkan karena keragaman data yang rendah, dimana didalam kuesioner responden cenderung memilih jawaban netral. Pengaruh kepuasan yang dirasakan oleh muzakki ternyata juga memiliki pengaruh yang positif dan signifikan terhadap loyalitas dengan nilai uji t sebesar 14,80 , yang berarti bahwa semakin tinggi kepuasan muzakki maka semakin tinggi loyalnya.

Tabel 3. Daftar nilai t hitung

\begin{tabular}{lccc}
\hline \multicolumn{1}{c}{ Lintasan } & Faktor Muatan & Uji t & Keterangan \\
\hline Compliance $\rightarrow$ Kepuasan & 0,45 & 5,68 & Signifikan \\
Assurance $\rightarrow$ Kepuasan & 0,38 & 7,24 & Signifikan \\
Reliability $\rightarrow$ Kepuasan & 0,25 & 2,83 & Signifikan \\
Tangible $\rightarrow$ Kepuasan & 0,04 & 0,35 & Tidak signifikan \\
Empathy $\rightarrow$ Kepuasan & 0,37 & 2,92 & Signifikan \\
Responsiveness $\rightarrow$ Kepuasan & 0,09 & 1,35 & Tidak signifikan \\
Kepuasan $\rightarrow$ Loyalitas & 0,78 & 14,80 & Signifikan \\
\hline
\end{tabular}


Dimensi kualitas pelayanan tertinggi yang memberikan dampak terhadap kepuasan muzakki ialah compliance dengan nilai faktor muatan sebesar 0,45 , yang berarti bahwa dimensi ini memberikan kontribusi yang relatif lebih besar dibanding dimensi lainnya dalam membentuk kepuasan muzakki. LAZ PKPU merupakan organisasi yang operasionalnya berdasarkan prinsip syariah sehingga dimensi compliance menjadi dimensi yang terpenting dan membedakan LAZ PKPU dengan organisasi lain pada umumnya. Dimensi selanjutnya ialah assurance, empathy dan reliability. Dimensi yang terendah ialah Tangible dengan nilai sebesar 0,04, yang berarti bahwa dimensi ini memberikan kontribusi yang paling kecil dalam membentuk kepuasan muzakki. Dimensi terendah lainnya ialah responsiveness dengan nilai faktor muatan sebesar 0,09 .

Berdasarkan Gambar 3, variabel indikator X1 sampai dengan X25 memiliki uji $t$ lebih besar dari 1,96 sehingga variabel-variabel tersebut memiliki hubungan yang signifikan dengan masing-masing variabel latennya. Hal ini berarti bahwa setiap dimensi kualitas pelayanan dipengaruhi oleh setiap indikator yang ada dalam dimensi tersebut.

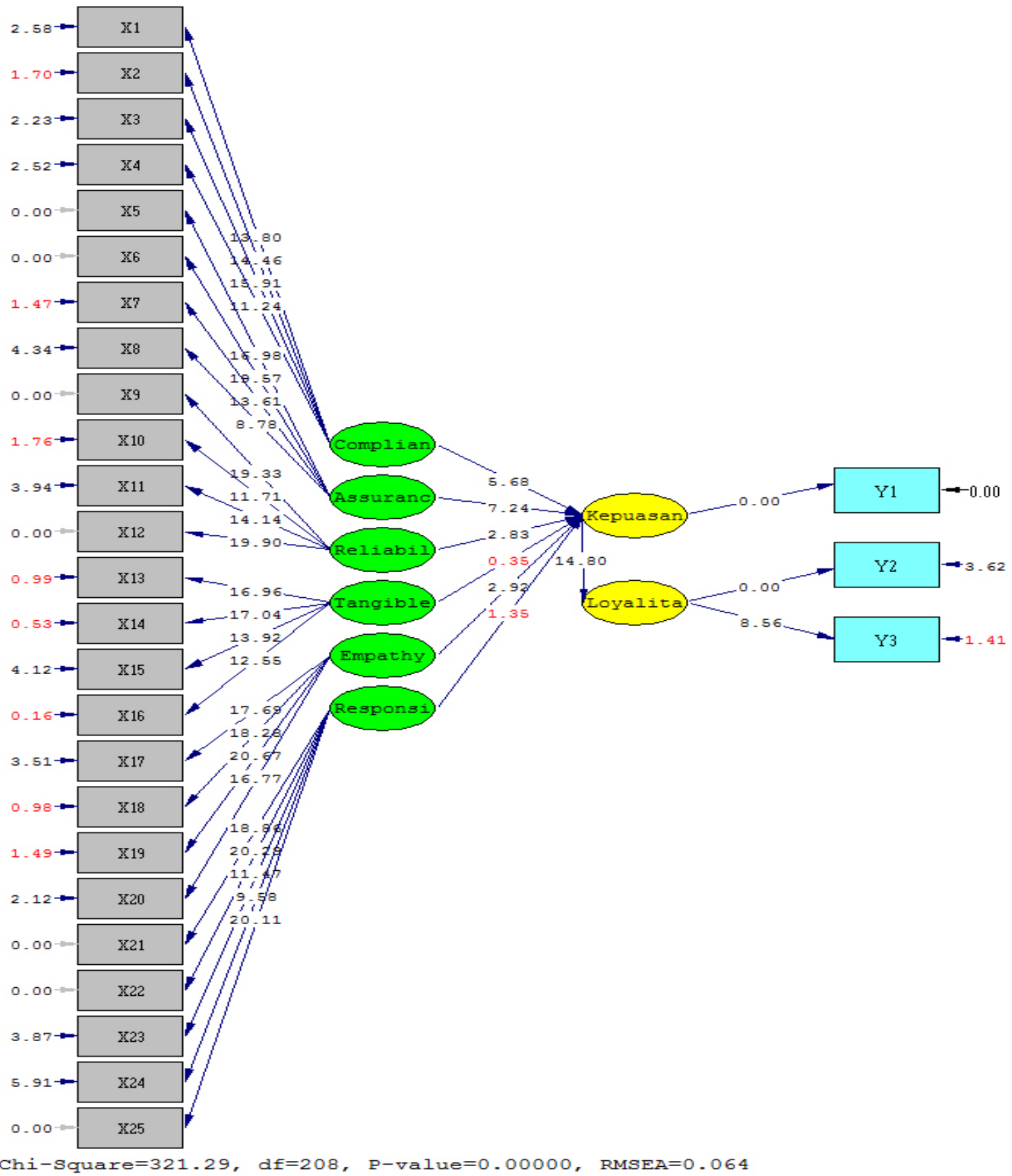

Gambar 3. Uji signifikansi (uji t) 
Tingkat Kepuasan Muzakki Atas Pelayanan yang Telah Diberikan LAZ PKPU Yogyakarta

Keseluruhan atribut dalam dimensi kepuasan dijadikan dasar perhitungan untuk indeks kepuasan muzakki. Perhitungannya berdasarkan pada bobot yang dihitung dari tingkat kinerja masing-masing atribut, yang dapat dilihat dalam Tabel 4. Hasil perhitungan tersebut, nilai yang diperoleh dari hasil perhitungan tingkat kepuasan responden sebesar $82,34 \%$ yang termasuk dalam kategori puas.

Tabel 1. Uji validitas dan reliabilitas

\begin{tabular}{|c|c|c|c|c|c|}
\hline No & Atribut & Mean & Mean & Weight & Weight \\
\hline & & Importance & Performance & Factor & Score \\
\hline & Compliance & Score & Score & & \\
\hline $\mathrm{X} 1$ & Pelaksanaan akad sesuai syariat Islam & 4,70 & 4,28 & 0,04214 & 0,18018 \\
\hline $\mathrm{X} 2$ & Perhitungan zakat sesuai syariat Islam & 4,71 & 4,30 & 0,0422 & 0,18141 \\
\hline $\mathrm{X} 3$ & Distribusi zakat sesuai syariat Islam & 4,71 & 4,32 & 0,0422 & 0,18236 \\
\hline \multirow[t]{2}{*}{$\mathrm{X} 4$} & $\begin{array}{l}\text { Media komunikasi dan sosialisasi zakat sesuai syariat } \\
\text { Islam }\end{array}$ & 4,52 & 4,21 & 0,04053 & 0,1706 \\
\hline & Assurance & & & & \\
\hline X5 & Karyawan ramah dan berprilaku sopan & 4,57 & 4,37 & 0,041 & 0,1793 \\
\hline X6 & Karyawan memahami hukum zakat & 4,72 & 4,27 & 0,04227 & 0,18044 \\
\hline $\mathrm{X} 7$ & $\begin{array}{l}\text { Karyawan mampu memberikan penjelasan dan } \\
\text { perhitungan zakat }\end{array}$ & 4,66 & 4,19 & 0,0418 & 0,17532 \\
\hline \multirow[t]{2}{*}{$\mathrm{X} 8$} & Jumlah karyawan mencukupi & 4,23 & 3,90 & 0,03792 & 0,14773 \\
\hline & Reliability & & & & \\
\hline X9 & PKPU selalu menepati janji & 4,63 & 4,18 & 0,04147 & 0,1733 \\
\hline $\mathrm{X} 10$ & Adanya fasilitas layanan online & 4,30 & 3,99 & 0,03852 & 0,15381 \\
\hline $\mathrm{X} 11$ & Adanya fasilitas layanan jemput zakat & 4,34 & 4,14 & 0,03886 & 0,16095 \\
\hline \multirow[t]{2}{*}{$\mathrm{X} 12$} & $\begin{array}{l}\text { Jika kesulitan, PKPU memberikan penjelasan dan } \\
\text { solusi }\end{array}$ & 4,51 & 4,15 & 0,0404 & 0,16762 \\
\hline & Tangible & & & & \\
\hline $\mathrm{X} 13$ & Kondisi kantor rapih, bersih dan teratur & 4,35 & 3,90 & 0,03899 & 0,1519 \\
\hline $\mathrm{X} 14$ & Ruang penerima tamu nyaman & 4,28 & 3,87 & 0,03839 & 0,14869 \\
\hline $\mathrm{X} 15$ & Fasilitas parkir nyaman & 4,25 & 3,57 & 0,03806 & 0,13604 \\
\hline \multirow[t]{2}{*}{ X16 } & Adanya bukti pembayaran dengan print-out & 4,31 & 3,99 & 0,03859 & 0,15408 \\
\hline & Empathy & & & & \\
\hline $\mathrm{X} 17$ & Jam operasional yang memudahkan & 4,45 & 4,10 & 0,03986 & 0,16332 \\
\hline $\mathrm{X} 18$ & Memberikan pemahaman zakat yang mudah dipahami & 4,55 & 4,21 & 0,0408 & 0,17172 \\
\hline $\mathrm{X} 19$ & Menerima kritik dan saran & 4,54 & 4,15 & 0,04067 & 0,16873 \\
\hline \multirow[t]{2}{*}{ X20 } & Publikasi dana zakat yang dihimpun & 4,59 & 4,19 & 0,04113 & 0,17221 \\
\hline & Responsiveness & & & & \\
\hline $\mathrm{X} 21$ & $\begin{array}{l}\text { Permasalahan zakat diselesaikan dengan cepat dan } \\
\text { segera }\end{array}$ & 4,55 & 4,09 & 0,0408 & 0,16685 \\
\hline $\mathrm{X} 22$ & Karyawan merespon dan menindaklanjuti keluh kesah & 4,48 & 4,07 & 0,04013 & 0,16322 \\
\hline $\mathrm{X} 23$ & Brosur dan proposal dikirim melalui SMS dan pos & 4,13 & 4,12 & 0,03699 & 0,15236 \\
\hline $\mathrm{X} 24$ & Laporan dikirim melalui email dan pos & 4,17 & 4,08 & 0,03739 & 0,15262 \\
\hline \multirow[t]{4}{*}{$\mathrm{X} 25$} & Ketersediaan brosur, leaflet yang informatif & 4,34 & 4,17 & 0,03888 & 0,16225 \\
\hline & Average & 4,46 & 4,11 & & \\
\hline & Jumlah & 111,58 & 102,81 & 1,00 & 4,12 \\
\hline & Tingkat kepuasan & & & & 82,34 \\
\hline
\end{tabular}




\section{Tingkat Loyalitas Muzakki Atas Pelayanan yang Telah Diberikan LAZ PKPU Yogyakarta}

Untuk menentukan tingkat loyalitas muzakki maka digunakan jawaban dari responden yang menjawab dengan nilai 4 (setuju) dan 5 (sangat setuju) pada atribut pernyataan Y2 (Kembali menggunakan jasa layanan) dan Y3 (Merekomendasikan kepada orang lain). Perhitungannya didasarkan pada top two boxes penilaian dari masing-masing atribut oleh responden yang dapat dilihat pada Tabel 5. Sesuai Tabel 5, nilai yang diperoleh dari hasil perhitungan tingkat loyalitas responden sebesar $84,7 \%$, yang termasuk dalam kategori loyal.

Tabel 5. Tingkat loyalitas

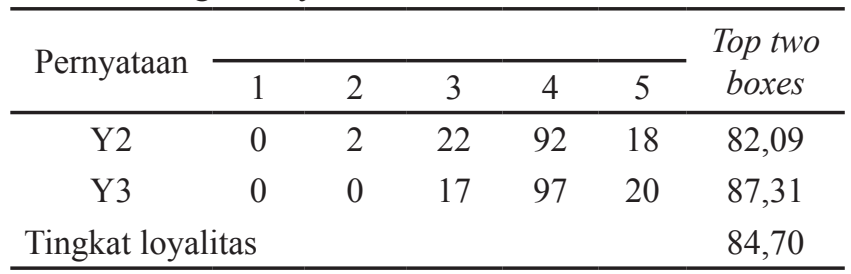

\section{Strategi LAZ PKPU Yogyakarta untuk Meningkatkan Pelayanan yang Lebih Baik}

Hasil tingkat kinerja dan kepentingan atribut yang dapat memberikan informasi pengaruh dimensi kepuasan yang signifikan dipetakan dalam diagram kartesius sehingga dapat memberikan informasi tentang posisi dari masing-masing atribut kinerja yang berpengaruh pada kualitas kepuasan muzakki, seperti terdapat dalam Gambar 4. Hal tersebut juga dapat dilihat posisi masing-masing atribut yang memengaruhi kepuasan muzakki sesuai dengan kuadrannya, dengan penjelasan sebagai berikut:

\section{Kuadran I}

Kuadran I (prioritas utama), merupakan wilayah yang memuat faktor-faktor yang dianggap penting oleh responden, tetapi pada kenyataannya faktor-faktor ini belum sesuai seperti yang diharapkan. Keberadaan atribut-atribut tersebut dinilai penting oleh responden dan nilainya berada di atas rata-rata tingkat kepentingan, namun nilainya masih berada di bawah rata-rata tingkat kinerja. Atribut-atribut tersebut adalah Permasalahan zakat diselesaikan dengan cepat dan segera (X21), karyawan merespon dan menindaklanjuti keluh kesah (X22).

\section{Kuadran II}

Kuadran II (pertahankan prestasi), merupakan wilayah yang memuat faktor-faktor yang dianggap penting oleh muzakki dan faktor-faktor yang dianggap oleh muzakki adalah sesuai dengan yang dirasakan sehingga tingkat kepuasannya relatif tinggi. Oleh sebab itu, atribut-atribut yang terdapat dalam kuadran ini perlu dipertahankan kinerjanya oleh manajemen dan dijaga kualitas pelayanannya karena secara umum telah sesuai dengan yang diharapkan muzakki. Atributatribut tersebut adalah pelaksanaan akad sesuai syariat Islam (X1), perhitungan zakat sesuai syariat Islam (X2), distribusi zakat sesuai syariat Islam (X3), media komunikasi dan sosialisasi zakat sesuai syariat Islam (X4), karyawan ramah dan berprilaku sopan (X5), karyawan memahami hukum zakat (X6), karyawan mampu memberikan penjelasan dan perhitungan zakat (X7), selalu menepati janji (X9), jika kesulitan, PKPU memberikan penjelasan dan solusi (X12), memberikan pemahaman zakat yang mudah dipahami (X18), menerima kritik dan saran (X19), publikasi dana zakat yang dihimpun (X20).

\section{Kuadran III}

Kuadran III (prioritas rendah), merupakan wilayah yang memuat faktor-faktor yang dianggap kurang penting oleh muzakki dan pada kenyataannya kinerjanya biasa saja. Namun, PKPU dapat memberikan layanan pada atribut yang masuk dalam kuadran ini sama baiknya dengan kuadran lainnya sehingga muzakki dapat menjadi lebih puas. Atribut tersebut adalah jumlah karyawan mencukupi (X8), fasilitas layanan online (X10), Kondisi kantor rapih, bersih dan teratur (X13), ruang penerima tamu nyaman (X14), fasilitas parkir nyaman (X15), bukti bayar dengan print out (X16), laporan dikirim melalui pos dan email (X24).

\section{Kuadran IV}

Kuadran IV (Berlebihan), merupakan wilayah yang memuat faktor-faktor yang dianggap kurang penting oleh responden dan dirasakan terlalu berlebihan. Atribut tersebut adalah fasilitas layanan jemput zakat (X11), brosur dan proposal dikirim melalui SMS dan pos (X23), ketersediaan brosur, leaflet yang informatif (X25). 


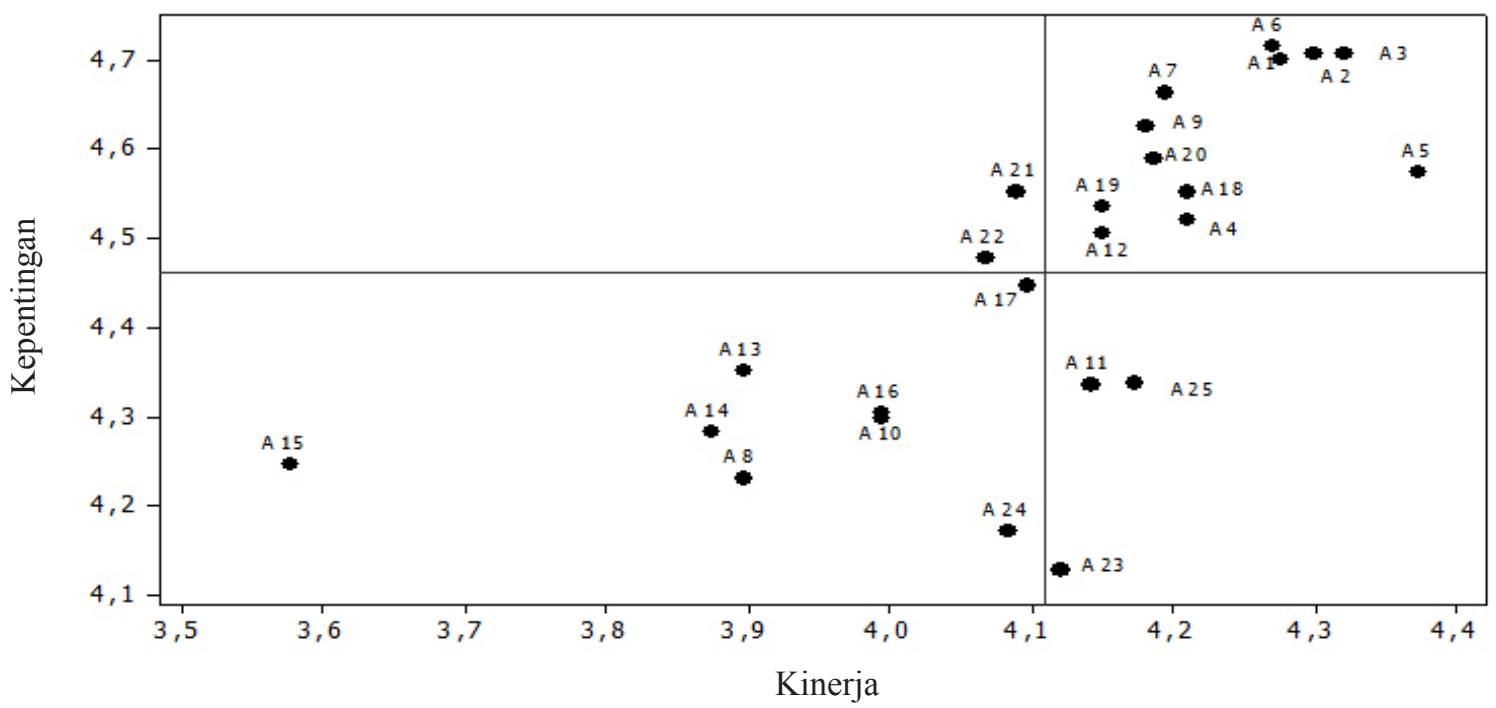

Gambar 4. Diagram kartesius tingkat kepentingan dan kinerja

\section{Implikasi Manajerial}

Sesuai hasil analisis SEM, terdapat dua dimensi yang tidak memberikan pengaruh terhadap kepuasan muzakki, yaitu tangible dan responsiveness. Variabel tangible yang terendah nilainya yang berarti paling tidak signifikan disebabkan adanya banyak cara yang dapat dilakukan muzakki untuk membayar zakat sehingga tidak perlu datang langsung ke kantor PKPU. Dimensi responsiveness juga tidak signifikan pengaruhnya disebabkan hubungan yang selama ini sudah terjalin baik hasil interaksi antara muzakki dengan tim relawan PKPU Yogyakarta. Peningkatan kualitas pelayanan dalam dimensi ini dapat berpengaruh kedepannya terhadap kepuasan muzakki.

Hasil penerapan IPA, terdapat dua indikator yang masuk dalam kuadran 1 yang berarti bahwa menurut muzakki indikator tersebut perlu untuk ditingkatkan kinerjanya yaitu indikator permasalahan zakat diselesaikan dengan cepat dan segera dan karyawan merespon dan menindaklanjuti keluh kesah. Sebaliknya, untuk indikator yang lain harus dipertahankan kinerjanya agar kepuasan muzakki tidak menurun.

Sebagai LAZ Nasional dengan operasionalnya sesuai syariah maka dimensi compliance memiliki peranan yang sangat penting. Sesuai hasil analisis SEM, keempat indikator yang ada dalam dimensi ini memberikan pengaruh yang signifikan terhadap kepuasan muzakki. PKPU dapat terus mengoptimalkan peran Biro Konsultasi Syariah secara internal dan eksternal. Secara internal melalui konsultasi dan pengawasan aktivitas dan program yang dilakukan. Untuk eksternal memberikan penjelasan kepada muzakki dan mustahik jika terdapat masalah yang terkait dengan ketaatan dan kepatuhan pada nilai syariah.

\section{KESIMPULAN DAN SARAN}

\section{Kesimpulan}

Hasil penelitian terhadap kepuasan dan loyalitas muzakki PKPU Yogyakarta maka dapat diambil kesimpulan bahwa terdapat empat dimensi yang berpengaruh terhadap kepuasan muzakki yang ditunjukkan dengan besarnya kontribusi yang diberikan. Keempat dimensi tersebut ialah assurance, compliance, empathy, dan reliability.

Hasil perhitungan tingkat kepuasan muzakki sebesar $82,34 \%$ menunjukkan muzakki telah merasa puas dengan layanan yang diberikan LAZ PKPU Yogyakarta. Hasil perhitungan tingkat loyalitas sebesar $84,7 \%$ juga menunjukkan bahwa muzakki telah loyal kepada LAZ PKPU Yogyakarta.

Hasil analisis IPA, LAZ PKPU Yogyakarta harus berupaya mempertahankan dan meningkatkan kualitas pelayanan kepada muzakki agar lebih baik terutama untuk indikator yang masuk dalam kuadran 1 dan 2 . Namun, bukan berarti kuadran 3 dan 4 diabaikan karena untuk tetap mempertahankan kepuasan muzakki, indikator dalam kuadran tersebut dapat berpengaruh di masa yang akan datang. 


\section{Saran}

Peningkatan dan perbaikan atribut pelayanan harus senantiasa dievaluasi dan ditingkatkan agar seluruh atribut dapat memberikan kontribusi positif terhadap dimensi pelayanan dan memberi pengaruh terhadap kepuasan dan loyalitas muzakki. Tingkat kepuasan dan loyalitas muzakki dapat ditingkatkan lagi dengan cara meningkatkan kualitas pelayanan yang telah dilakukan selama ini. Penelitian selanjutnya bisa dilakukan terhadap pelayanan yang diberikan LAZ kepada mustahik. Sebagai LAZ, pelayanan yang diberikan tidak hanya kepada muzakki namun juga kepada mustahik. Hal ini berbeda dengan perusahaan atau lembaga lain pada umumnya yang hanya terkait pada pelayanan terhadap pelanggan saja. Dengan mengetahui kualitas pelayanan kepada mustahik maka LAZ dapat mengevaluasi kualitas layanan programprogram yang telah dilakukan.

\section{DAFTAR PUSTAKA}

Adnan MA. 2001. Sebuah Kata Pengantar dalam Buku Akuntansi dan Manajemen Keuangan Organisasi Pengelola Zakat. Jakarta: Institut Manajemen Zakat.

Aryani, Rosinta. 2010. Pengaruh kualitas layanan terhadap kepuasan pelanggan dalam membentuk loyalitas pelanggan. Jurnal Ilmu Administrasi dan Organisasi 17(2): 114-126.
Ashari H, Sumarwan U, Kirbrandoko. 2013. Kepuasan pelaku usaha terhadap kualitas layanan perizinan pupuk di Kementerian Pertanian. Jurnal Manajemen \& Agribisnis 10(3):156-164.

Beik IS. 2009. Analisis peran zakat dalam mengurangi kemiskinan (Studi kasus dompet dhuafa Republika. Jurnal Pemikiran dan Gagasan 2(2009):32-46.

Bramasetia SA. 2014. Penghimpunan dana ziswaf terus meningkat. http://www. republika.co.id. [8 Oktober 2015].

Despriyatmoko G, Syarief R, Maulana A. 2016. Tingkat kepuasan terhadap kualitas pelayanan pemeliharaan data pendaftaran tanah di kantor pertanahan Kabupaten Bogor. Jurnal Aplikasi Bisnis dan Manajemen 2(2):172-182.

Hair JFJ, Lack WC, Babin BJ, Anderson RE, Tatham RL. 2006. Multivariate Data Analysis. United States: Pearson Education, Inc.

Othman, Owen. 2002. The multi dimensionality of Carter Model to measure customer service quality (SQ) in Islamic Banking Industry: A Study in Kuwait Finance House. International Journal of Islamic Financial Services 3(1):1-26.

Ristanti V, Shihab MS, Rekarti E. 2011. Pengaruh dimensi kualitas pelayanan dan loyalitas terhadap loyalitas pelanggan. Jurnal Manajemen dan Bisnis Sriwijaya 9(17):1-12. 